\title{
BIOLIXIVIAÇÃO DE SULFETOS SECUNDÁRIOS DE COBRE POR ACIDITHIOBACILLUS FERROOXIDANS
}

Flávio Luciano dos Santos Cruz '

Flavio Luiz Martins ' Liliane Coelho de Carvalho' Victor Alvarenga'

Versiane Albis Leão'

\section{Resumo}

Neste trabalho, foi investigada a biolixiviação de sulfetos secundários de cobre com Acidithiobacillus ferrooxidans. $\mathrm{O}$ efeito dos parâmetros $\mathrm{pH}$, concentração dos cátions $\mathrm{Fe}^{2+}, \mathrm{Al}^{3+}$ e $\mathrm{Mg}^{2+}$, sob a extração de cobre foram avaliados. Os experimentos em frascos agitados mostraram elevadas recuperações de cobre próximas a $75 \%$. A cinética de extração do metal foi afetada pelo $\mathrm{pH}$ e concentração de $\mathrm{Fe}^{2+}$ e os valores ideais foram I,6-I,8 e 5-10 g. $\mathrm{L}^{-1}$, respectivamente. $A$ adição de fontes externas de alumínio (até $5 \mathrm{~g} \mathrm{~L}^{-1}$ ) favoreceu a biolixiviação devido à complexação do íon fluoreto liberado durante a dissolução do mineral.

Palavras-chave: Biolixiviação; Cobre; Acidithiobacillus ferrooxidans.

\section{BIOLIXIVIATION OF SECONDARY COPPER SULPHATES BY ACIDITHIOBACILLUS FERROOXIDANS}

\begin{abstract}
This work investigated the bioleaching of secondary copper ores (chalcocite and bornite) by a mesophile culture comprised mostly of Acidithiobacillus ferrooxidans. $\mathrm{O}$ efeito dos parâmetros $\mathrm{pH}$, concentração dos cátions $\mathrm{Fe}^{2+}, \mathrm{Al}^{3+} \mathrm{e}$ $\mathrm{Mg}^{2+}$, sob a. Experiments were performed in Erlenmeyer flasks $(250 \mathrm{~mL})$ containing $100 \mathrm{~mL}$ of a $5 \%(\mathrm{w} / \mathrm{v})$ pulp stirred at $150 \mathrm{~min}^{-1}$. The effects of $\mathrm{pH}, \mathrm{Fe}^{2+}, \mathrm{Al}^{3+}$ and $\mathrm{Mg}^{2+}$ concentrations on copper extraction were determined. The leaching kinetics from the marginal ore was slightly affected by both $\mathrm{pH}$ and ferrous iron concentrations and the largest leaching rates were observed at $\mathrm{pH} \mathrm{I}, 6-\mathrm{I}, 8$ and $5-10 \mathrm{~g} \cdot \mathrm{L}^{-1} \mathrm{Fe}^{2+}$. Aluminum concentrations (up to $5 \mathrm{~g} \cdot \mathrm{L}^{-1}$ ) improved the copper extraction kinetics as fluoride ions were complexed by the element and the final copper extraction reached $75 \%$.
\end{abstract}

Keywords: Bioleaching; Copper; Acidithiobacillus ferrooxidans.

\section{INTRODUÇÃO}

A produção de cobre metálico, a partir de seus minérios, é definida pelo tipo de mineral no qual o elemento se encontra. Os minerais sulfetados, por exemplo, são processados por rotas pirometalúrgicas, onde obtém-se cerca de mais de $95 \%$ de extração do cobre presente no mineral. Entretanto, os processos pirometalúrgicos, devido às suas características intrínsecas, só são capazes de processar concentrados ou minérios de alto teor, o que exige, quase sempre, uma etapa de concentração do minério de cobre anterior à metalurgia do metal [I].

A hidrometalurgia é uma alternativa ao processamento pirometalúrgico de sulfetos metálicos. Como vantagens da primeira em relação à segunda, podem-se citar (i) a possibilidade de se tratar minérios de baixo teor, rejeitos, e minérios marginais, o que aumenta a vida útil dos depósitos minerais e (ii) poder-se processar minérios de natureza complexa e contendo impurezas. O estudo da hidrometalurgia de sulfetos de cobre recebeu grande atenção nas décadas de 1970 e 1980 como uma forma de se estabelecer uma alternativa à pirometalurgia do cobre, grande produtora de dióxido de enxofre [2]. As pesquisas envolveram a lixiviação química na presença de oxigênio e íons $\mathrm{Fe}^{3+}$ como agentes oxidantes do mineral. Paralelamente, a partir dos anos 1980, consolidaram-se os processos bio-hidrometalúrgicos

'Laboratório de Bio\&Hidrometalurgia, Departamento de Engenharia Metalúrgica e de Materiais, Universidade Federal de Ouro Preto - UFOP, Ouro Preto, MG, Brasil. E-mail: flavioluciano@hotmail.com 
aplicados aos minérios de cobre. A biolixiviação baseia-se na atividade de micro-organismos mesófilos, termófilos moderados e/ou termófilos extremos, que suprem suas necessidades energéticas com a oxidação de íons $\mathrm{Fe}^{2+}$ e compostos reduzidos de enxofre, tendo como resultado a solubilização dos metais [I]. Vários estudos sobre a dissolução de sulfetos minerais, com a utilização de bactérias, têm sido realizados utilizando micro-organismos mesófilos, especialmente Acidithiobacillus ferrooxidans [3].

A grande parte dos sulfetos secundários de cobre como calcocita, bornita e covelita, podem ser biolixiviada com eficiência por micro-organismos. No entanto, a biolixiviação da calcopirita, ainda é um desafio devido à cinética lenta e a baixa extração [4]. Segundo Olson [5], os minérios que não respondem satisfatoriamente à biolixiviação/solubilização, são conhecidos como minérios refratários, sendo a presença da calcopirita a principal causa de refratariedade.

Uma das particularidades essenciais apresentada por Acidithiobacillus sp. é a sua grande resistência a concentrações elevadas de íons metálicos, o que torna possível a sua aplicação nos processos de biolixiviação de sulfetos metálicos $[6,7]$. Frequentemente é possível adaptar linhagens individuais a altas concentrações de metais ou a substratos específicos pelo aumento gradual da concentração do metal ou do substrato [8]. Entretanto, tais bactérias apresentam baixa tolerância a ânions como o íon fluoreto, que é um potente inibidor do crescimento microbiano nas condições de $\mathrm{pH}$ dos processos de biolixiviação. O fluoreto de sódio em concentração igual a $20 \mathrm{mg} . \mathrm{L}^{-1}$ de $\mathrm{F}$ provoca a completa inibição da oxidação bacteriana do íon $\mathrm{Fe}^{2+}$. Este íon, em sistemas de biolixiviação (meio ácido), é convertido a HF, que atravessa a membrana celular da bactéria e, posteriormente, dissocia-se na forma dos íons $\mathrm{H}^{+}$e F. A presença do íon $\mathrm{H}^{+}$ reduz $\circ \mathrm{pH}$ interno da célula (que é neutro) o que resulta na morte da mesma [9]. O efeito deletério do íon fluoreto pode ser minimizado pela adição de sais de alumínio, os quais complexam o ânion e reduzem a concentração de HF no sistema [10].

\section{MATERIAIS E MÉTODOS}

Neste trabalho utilizou-se uma amostra de sulfetos secundários de cobre cedida pela empresa Vale, para os ensaios de biolixiviação. Por apresentar baixo teor de cobre a amostra foi denominada como minério marginal. Essa amostra foi peneirada segundo a série Tyler e para a realização dos ensaios foi utilizada a faixa granulométrica retida em $-75+53 \mu \mathrm{m}$. Para determinação dos teores dos elementos presentes na amostra foi realizada digestão ácida utilizando-se ácido clorídrico e nítrico, analisados por espectrometria de emissão atômica com fonte de plasma (equipamento Varian, modelo 725). Os resultados obtidos foram: Cu:I,4\%; Fe:29,02; F:0,6I\%; Cl:0,58; Al: 4,77\% e Mg: $0,98 \%$.

A amostra do minério marginal é constituída, principalmente por biotita $(34,9 \%)$ e magnetita $(9,5 \%)$ e dos grupos mineralógicos anfibólios $(25,2 \%)$ e granada (16,7\%) - analisada em um microscópio JEOL JSM 55 I0, na forma de pó em uma fita condutora à base de carbono, sendo a espectroscopia por energia dispersiva (EDS) utilizada para a análise elementar.

Pode-se destacar nessa análise a presença de I, I\% de sulfetos de cobre do minério marginal. Além disso, é importante destacar a presença da fluorita no minério. Em termos da partição de cobre, o elemento encontra-se predominantemente sob a forma de calcocita e bornita, sendo que a amostra também apresenta cerca de $6 \%$ de calcopirita. Os resultados das análises de cobre solúvel para a amostra indicaram que a maior parte do cobre é solúvel em cianeto de potássio (aproximadamente $85 \%$ ), seguido de ácido acético (4-8\%). Os resultados também mostram que $6,8 \%$ de cobre no minério marginal, estão em fases insolúveis. Logo o predomínio de sulfetos secundários foi confirmado [II].

\section{I Ensaios de Biolixiviação com Micro-Organismos Mesófilos}

Os experimentos de biolixiviação foram conduzidos com micro-organismos mesófilos, composto predominante por Acidithiobacillus ferrooxidans, cepa isolada de uma mina de sulfetos, o qual foi cultivado em meio seletivo (contendo íons $\mathrm{Fe}^{2+}$ e em pH igual a I,8).

Inicialmente, experimentos foram realizados em batelada, em Erlenmeyers de $250 \mathrm{~mL}$, contendo $100 \mathrm{~mL}$ de solução, $5 \%$ de sólidos $(\mathrm{p} / \mathrm{v})$ e volume de inóculo de $10 \%(\mathrm{v} / \mathrm{v})$ contendo íons $\mathrm{Fe}^{2+}$ e população bacteriana na ordem de $10^{8}$ células. $\mathrm{mL}^{-1}$. Os frascos foram agitados a $150 \mathrm{~min}^{-1}$ e mantidos a temperatura de $35^{\circ} \mathrm{C}$ em um "shaker" termostatizado (Equipamento New Brunswick Scientific, INNOVA 44). Foi empregado o meio de cultura Norris com $10 \%(\mathrm{v} / \mathrm{v})$, com os seguintes sais nas seguintes concentrações: $\left(\mathrm{NH}_{4}\right)_{2} \mathrm{SO}_{4}: 0,4 \mathrm{~g} \cdot \mathrm{L}^{-1} ; \mathrm{MgSO}_{4} \cdot 7 \mathrm{H}_{2} \mathrm{O}: 0,8 \mathrm{~g} \cdot \mathrm{L}^{-1}$ e $\mathrm{K}_{2} \mathrm{HPO}_{4}: 0,4 \mathrm{~g} \cdot \mathrm{L}^{-1}$.

Foi avaliada a viabilidade do crescimento bacteriano na presença do minério marginal. Os ensaios foram realizados com volume de inóculo de $10 \%(\mathrm{v} / \mathrm{v})$ e a condição de referência foi fixada para o valor de $\mathrm{pH}$ em I,8, o tamanho de partícula em $-75+53 \mu \mathrm{m}$ e a concentração de $\mathrm{Fe}^{2+} \mathrm{em}$ 2 g.L.-1. Essa mesma condição foi utilizada nos ensaios de controle químico (na ausência de micro-organismos). Após a confirmação do crescimento bacteriano foram estudados os efeitos da variação do $\mathrm{pH}$ e da concentração de íons $\mathrm{Fe}^{2+}$, $\mathrm{Al}^{3+}$ e $\mathrm{Mg}^{2+}$ na biolixiviação do minério marginal, em ensaios em bancada (Erlenmeyers). Os valores de $\mathrm{pH}$ estudados foram I,4, I,6, I,8, 2,0 e 2,2 e as concentrações de $\mathrm{Fe}^{2+}$ estudadas foram: 0, 2, 5 e 10 g. $\mathrm{L}^{-1}$. Os íons $\mathrm{Mg}^{2+}$ e Al ${ }^{3+}$ foram avaliados separadamente utilizando os valores de $0 \mathrm{~g} \cdot \mathrm{L}^{-1}, 2 \mathrm{~g} \cdot \mathrm{L}^{-1}$ e $5 \mathrm{~g} . \mathrm{L}^{-1}$.

$\mathrm{O}$ pH e o potencial de oxidação (Eh) da suspensão foram medidos diariamente. $\mathrm{O}$ pH foi medido (Equipamento Digimed DM22) e ajustado, quando necessário, pela adição 
de solução I mol.L-1 de $\mathrm{H}_{2} \mathrm{SO}_{4}$ ou 6 mol.L-1 $\mathrm{NaOH}$. As perdas por evaporação foram compensadas pela adição de água destilada. $O$ Eh foi medido com relação ao eletrodo de platina com solução de $\mathrm{Ag}$ saturada com $\mathrm{AgCl}(\mathrm{Ag} / \mathrm{AgCl})$ (Equipamento Digimed DM20). Timol foi usado como bactericida nos ensaios de controle químico.

A concentração de cobre, e dos íons $\mathrm{Fe}^{2+}$ e $\mathrm{Fe}^{3+}$ foram medidas em intervalos regulares de tempo. $\mathrm{O}$ teor de cobre e ferro total, em cada experimento, foi determinado por ICP-OES varian 725. A concentração dos íons $\mathrm{Fe}^{2+}$ foi obtida por titulação com solução padrão de dicromato de potássio em um equipamento Schott titroline alpha. Por fim, a concentração dos íons $\mathrm{Fe}^{3+}$ foi determinada por diferença entre a concentração de ferro total e a concentração dos íons $\mathrm{Fe}^{2+}$.

A dissolução de íon fluoreto foi observada a partir da amostra estudada, com impacto negativo nos ensaios de biolixiviação. Esse efeito foi contornado com a adição de íons alumínio ao sistema. Com isso, a não ser em casos específicos, sulfato de alumínio foi adicionado ao sistema de biolixiviação para se atingir uma razão mássica $\mathrm{Al} / \mathrm{F}$ igual a 2,0 no início dos ensaios com o minério marginal, como descrito por Sicupira et al. [10].

\section{RESULTADOS E DISCUSSÃO}

\section{I Estudo do Efeito do pH na Extração do Cobre}

Nesta série de experimentos, foi estudada a biolixiviação do minério marginal utilizando a cepa de Acidithiobacillus ferrooxidans, previamente caracterizada por técnicas moleculares [12]. Foram realizados ensaios para estudar a influência do $\mathrm{pH}$, nos valores de I,4 a 2,2, sobre o percentual de extração do cobre. A Figura I mostra o percentual de extração de cobre em função do tempo nos experimentos realizados. A extração de cobre foi lenta e houve efeito do
$\mathrm{pH}$ na extração do metal, sendo que o $\mathrm{pH} \mathrm{I,8} \mathrm{obteve} \mathrm{a}$ maior extração de cobre $(75 \%)$, em relação ao ensaio de controle químico (20\%).

A extração observada para o minério marginal (75\%) é devida, possivelmente, à presença da calcopirita. A calcopirita é um mineral de cobre muito refratário e, por isso, não susceptível para processos hidrometalúrgicos. Sabe-se que a reação de oxidação da calcopirita utilizando íons férricos possui uma cinética lenta e sua taxa de oxidação diminui com o tempo. Isso é atribuído à formação de uma camada de passivação durante a lixiviação em condições oxidantes, o que inibe a reação [13].

Sicupira et al. [10] demonstraram que o pH é uma importante variável na lixiviação química dos sulfetos de cobre estudados neste trabalho, sendo que elevadas extrações são obtidas apenas em condições de acidez mais elevada ( $\mathrm{pH} \mathrm{I}$,4). Entretanto, como pode ser observando na Figura I, elevadas extrações de cobre podem ser obtidas em pH I,8 nos experimentos bióticos. Logo, pode-se inferir que a biolixiviação permite uma elevada extração de cobre com menor consumo de ácido em relação aos experimentos bióticos. Esses resultados são consistentes com o trabalho de Muñoz et al. [14] que estudaram o efeito do $\mathrm{pH}(1,5-3,0)$ na extração de urânio e no consumo de ácido, utilizando micro-organismos mesófilos. Para os autores, a maior extração (80\%) foi alcançado no valor de $\mathrm{pH} 2,5$, onde obteve-se um consumo de ácido $5 \mathrm{~g} / \mathrm{Kg}$ de minério. Para os valores de $\mathrm{pH}$ I,5 e 2,0, a extração foi elevada porém o consumo de ácido cresceu para $60 \mathrm{~g} / \mathrm{Kg}$ de minério e $20 \mathrm{~g} / \mathrm{Kg}$ de minério, respectivamente. Dopson et al. [15] estudaram o consumo de ácido em colunas de biolixiviação. Segundo os autores, após 293 dias de experimento, o consumo de ácido para os valores de $\mathrm{pH}$ nos ensaios iguais a I,5; 2,0; 2,5 e 3,0 foi de 219,$0 ; 79,0 ; 15,0$, e 5,0 g de $\mathrm{H}_{2} \mathrm{SO}_{4} / \mathrm{kg}$ de minério, respectivamente, o que também está de acordo com os resultados de Deveci et al. [16].
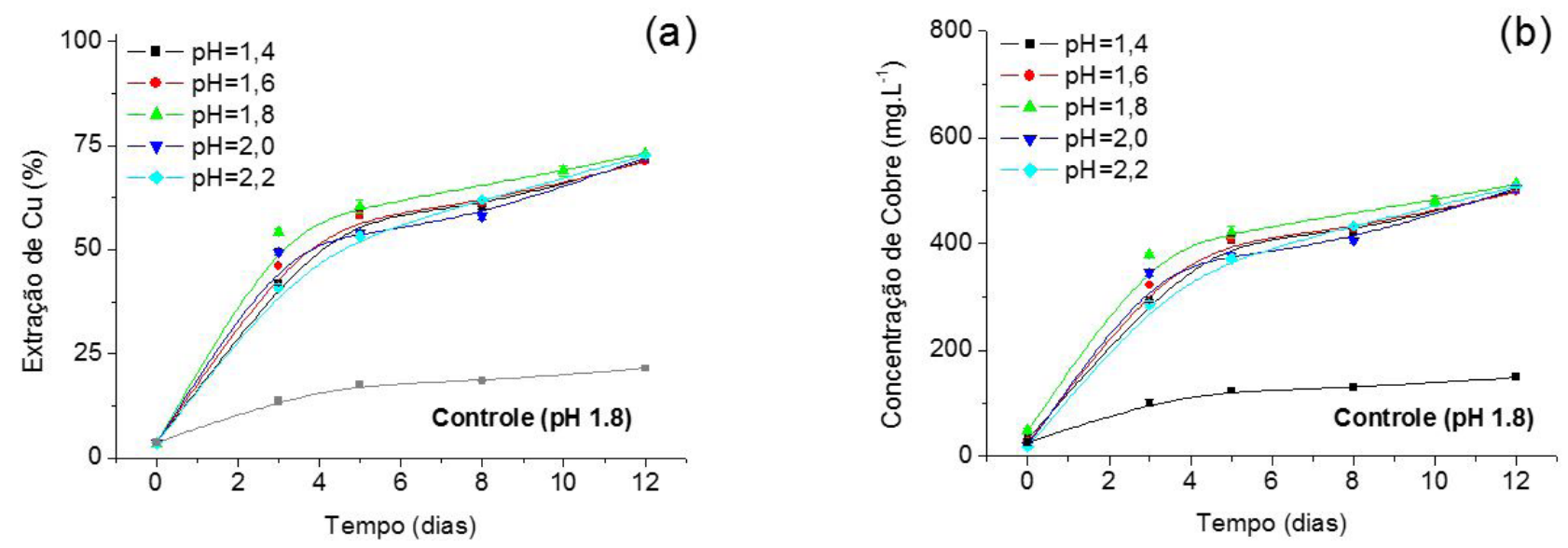

Figura I. Evolução do percentual de extração (a) e da concentração (b) de cobre com o tempo, em função do pH nos experimentos realizados com o minério marginal de cobre. Condições experimentais: $2 \mathrm{~g} . \mathrm{L}^{-1} \mathrm{Fe}^{2+}, 0,5 \mathrm{~g} \cdot \mathrm{L}^{-1} \mathrm{Al} \mathrm{l}^{3+}, 5 \%$ sólidos $(\mathrm{p} / \mathrm{v})$, meio de cultura Norris, I0\% ( $\left.\mathrm{v} / \mathrm{v}\right)$ de inoculo, $-75 \mu \mathrm{m}+53 \mu \mathrm{m}, 150 \mathrm{~min}^{-1}$ e $35^{\circ} \mathrm{C}$. 


\subsection{Estudo do Efeito da Concentração Inicial de $\mathrm{Fe}^{2+}$ na Extração de Cobre}

Foram também realizados ensaios para estudar o efeito da adição de sulfato ferroso sobre o percentual de extração de cobre nos sistemas de biolixiviação. As concentrações iniciais de $\mathrm{Fe}^{2+}$ estudadas foram: 0; 2,0; 5,0 e I0,0 g.L.-1 [16, I 7].

A Figura 2 mostra o percentual de extração de cobre e a concentração de ferro total para diferentes concentrações iniciais de $\mathrm{Fe}^{2+}$. A concentração inicial de íons $\mathrm{Fe}^{2+}$ não influenciou na extração de cobre, pois observou-se praticamente as mesmas extrações independentemente das concentrações iniciais de $\mathrm{Fe}^{2+}$, ou seja, $75 \%$. O ensaio controle mostrou uma extração bem menor, aproximadamente $40 \%$, o que evidenciou a importância da presença da bactéria.

Deveci et al. [16] estudaram o efeito da concentração inicial de $\mathrm{Fe}^{2+}$ na extração de zinco de um minério que possuía $2,89 \%$ de ferro. O ensaio controle e o experimento sem a adição de $\mathrm{Fe}^{2+}$ alcançaram extrações de $30 \%$ e $40 \%$, respectivamente, enquanto os ensaios com concentração de $\mathrm{Fe}^{2+}$ na faixa I a 4 g. $\mathrm{L}^{-1}$ mostraram resultados de aproximadamente $100 \%$ de extração. Pina et al. [18] também encontraram resultados semelhantes para um minério com $12 \%$ de ferro, onde a concentração inicial de $\mathrm{Fe}^{2+}$, superior a 2 g.L.-1, não interferiu na extração de zinco.

O aumento na concentração inicial de ferro total no sistema leva a uma maior precipitação de $\mathrm{Fe}^{3+}$ [19]. De acordo com a Figura $2 \mathrm{~b}$, para o ensaio com $10 \mathrm{~g} . \mathrm{L}^{-1}$ de $\mathrm{Fe}^{2+}$, a concentração de ferro reduz-se de cerca de $12 \mathrm{~g} \cdot \mathrm{L}^{-1}$ para valores ao redor de $8 \mathrm{~g} \cdot \mathrm{L}^{-1}$, enquanto a concentração final de ferro total situa-se abaixo de $4 \mathrm{~g} . \mathrm{L}^{-1}$ nas outras condições estudadas. No presente trabalho observa-se que apesar dos resultados finais de concetração de ferro, tanto nos ensaios com valores de $\mathrm{pH}$ elevados $(2,0$ e 2,2), como nos experimentos com concentrações iniciais de $\mathrm{Fe}^{2+}$ elevadas (5 g.L.-1 e 10 g.L.-1), a extração de cobre foi significativa. Isso aconteceu porque antes do $3^{\circ}$ dia de ensaio, a extração de cobre já havia alcançado valores elevados.

\subsection{Efeito da Concentração Inicial de $\mathbf{M g}^{2+}$ Sobre a Extração de Cobre}

Foram ainda realizados ensaios para estudar a influência da concentração de íons $\mathrm{Mg}^{2+}$ e $\mathrm{Al}^{3+}$ sobre o percentual de extração de cobre em sistemas de biolixiviação com Acidithiobacillus ferrooxidans, sendo que o efeito de cada íon foi estudado separadamente. As concentrações dos íons $\mathrm{Mg}^{2+}$ e $\mathrm{Al}^{3+}$ estudadas foram: 0, 2,0 e 5,0 g. $\mathrm{L}^{-1}$, como avaliado por Sicupira [ I I], indicaram a necessidade de "bleeding" nas soluções quando as concentrações de alumínio e magnésio atingiam valores próximos a $5 \mathrm{~g} \cdot \mathrm{L}^{-1}$, que estavam associados a elevados teores de sulfato.

A Figura 3 mostra o percentual de extração de cobre e a evolução do potencial de oxidação em função do tempo, para diferentes concentrações de íons $\mathrm{Mg}^{2+}$, nos experimentos realizados com o minério marginal. $\mathrm{Na}$ faixa de concentração estudada, houve um pequeno aumento na extração de cobre, para a amostra, como o aumento da concentração de $\mathrm{Mg}^{2+}$. Estudos semelhantes com micro-organismos termófilos moderados mostraram que na concentração de $10 \mathrm{~g} \cdot \mathrm{L}^{-1} \circ \mathrm{Mg}^{2+}$ reduziu a velocidade de extração de cobre, embora, no final do experimento, todas as condições estudadas alcançaram praticamente as mesmas extrações. Ojumu et al. [20] reportaram que concentrações de magnésio superiores a $10 \mathrm{~g} . \mathrm{LL}^{-1}$ afetaram a taxa de crescimento de Leptospirillum ferriphilum e logo a velocidade de oxidação dos íons ferrosos. Da mesma forma, Li e Ke [2I] mostraram que a oxidação de íons ferrosos por Acidithiobacillus ferrooxidans foi completamente inibida pela presença de 20,5 g.L.-1 de magnésio. A análise dos valores de Eh (Figura 3b) também não indicou efeito significativo no potencial de oxidação [22].
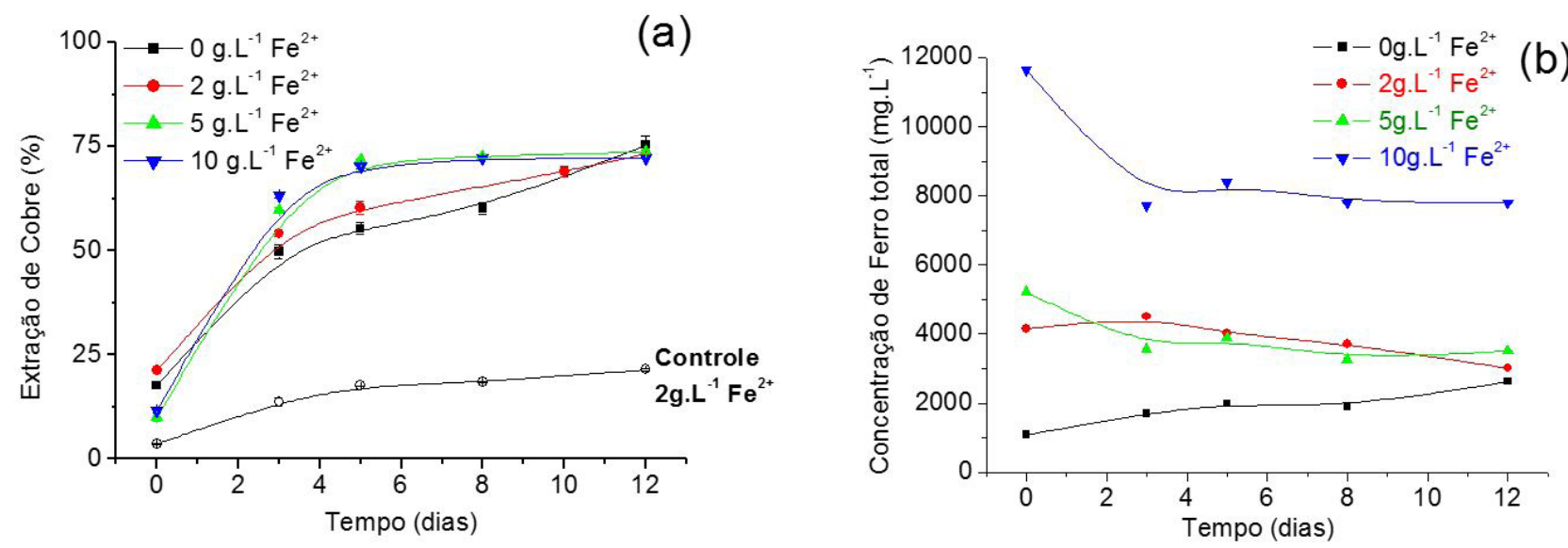

Figura 2. Efeito da concentração inicial de sulfato ferroso sobre extração de cobre (a) e concentração de ferro total (b) nos ensaios com minério marginal de cobre. Condições experimentais: $0,5 \mathrm{~g} \cdot \mathrm{L}^{-1} \mathrm{Al}^{3+}, 5 \%$ sólidos $(\mathrm{p} / \mathrm{v})$, meio de cultura Norris, $10 \%(\mathrm{v} / \mathrm{v})$ de inoculo, $-75+53 \mu \mathrm{m}, \mathrm{pH}$ inicial I,8, $150 \mathrm{~min}^{-1}$ e $35^{\circ} \mathrm{C}$. 
O aumento da concentração de magnésio é responsável pelo aumento da força iônica da solução lixiviante. Segundo Ojumu et al. [20] com o aumento da força iônica uma maior quantidade de energia é necessária para neutralizar o gradiente osmótico existente entre o interior e o exterior da célula. Esse maior gasto de energia afetaria negativamente a taxa de oxidação de $\mathrm{Fe}^{2+}$ e a concentração de biomassa no sistema. De qualquer forma, a concentração de $\mathrm{Mg}^{2+}$ ou de outro elemento considerada tóxica aos micro-organismos depende tanto das condições do processo de biolixiviação quanto das espécies de micro-organismos envolvidas. Como mostrado acima, a concentração de magnésio que prejudica, por exemplo, a oxidação de íons ferrosos por Leptospirillum ferriphilum não é a mesma reportada para Acidithiobacillus ferrooxidans. Logo, o estudo da concentração de determinado cátion que pode ser introduzida a um processo de biolixiviação deve ser realizado de maneira específica, levando-se em consideração os micro-organismos

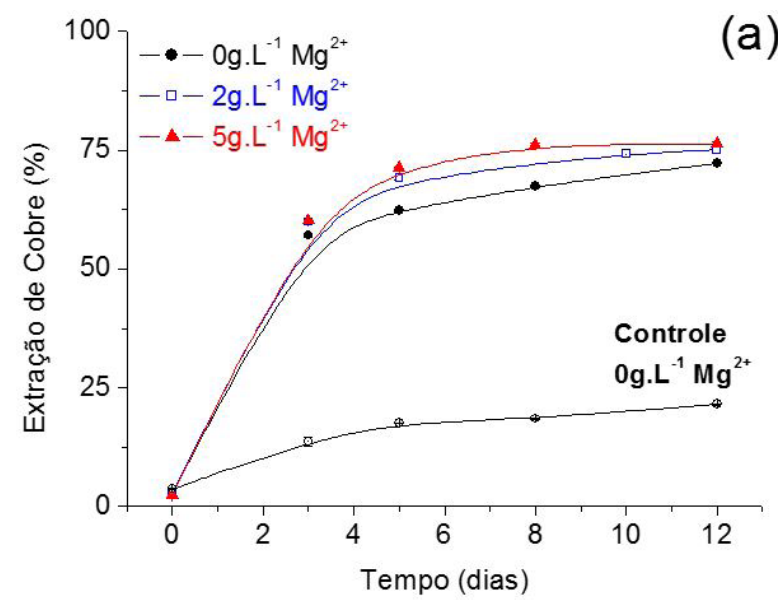

envolvidos, as características do minério ou concentrado a ser processado e o modo de processamento do mesmo.

\subsection{Efeito da Concentração Inicial de $\mathrm{Al}^{3+}$ Sobre Extração de Cobre}

A Figura 4 mostra a evolução do percentual de extração de cobre e do Eh em função do tempo, para diferentes concentrações de $\mathrm{Al}^{3+}$, nos experimentos realizados com o minério marginal. A concentração de $\mathrm{Al}^{3+}$ teve influência sobre extração de cobre, pois a velocidade de extração do metal foi menor nos ensaios sem o íon $\left(0 \mathrm{~g} . \mathrm{L}^{-1}\right)$. Sendo alcançado o máximo de $75 \%$ de extração na presença de 2 e 5 g. L $^{-1}$ de $\mathrm{Al}^{3+}$, em comparação a $60 \%$ nos experimentos sem adição externa de íons $\mathrm{Al}^{3+}$. De qualquer forma, na ausência de alumínio, a biolixiviação foi apenas afetada pois, no ensaio controle a extração foi menor que $40 \%$. A facilidade de Acidithiobacillus ferrooxidans em crescer na

Figura 3. Efeito da presença de magnésio sobre extração de cobre (a) e o potencial de oxidação (b) nos ensaios com minério marginal de cobre. Condições experimentais: $2 \mathrm{~g} \cdot \mathrm{L}^{-1} \mathrm{Fe}^{2+}, 0,5 \mathrm{~g} \cdot \mathrm{L}^{-1} \mathrm{Al}^{3+}, 5 \%$ sólidos $(\mathrm{p} / \mathrm{v})$, meio de cultura Norris, $10 \%(\mathrm{v} / \mathrm{v})$ de inoculo, $-75+53 \mu \mathrm{m}, \mathrm{pH}$ inicial I,8, $150 \mathrm{~min}^{-1}$ e $35^{\circ} \mathrm{C}$.
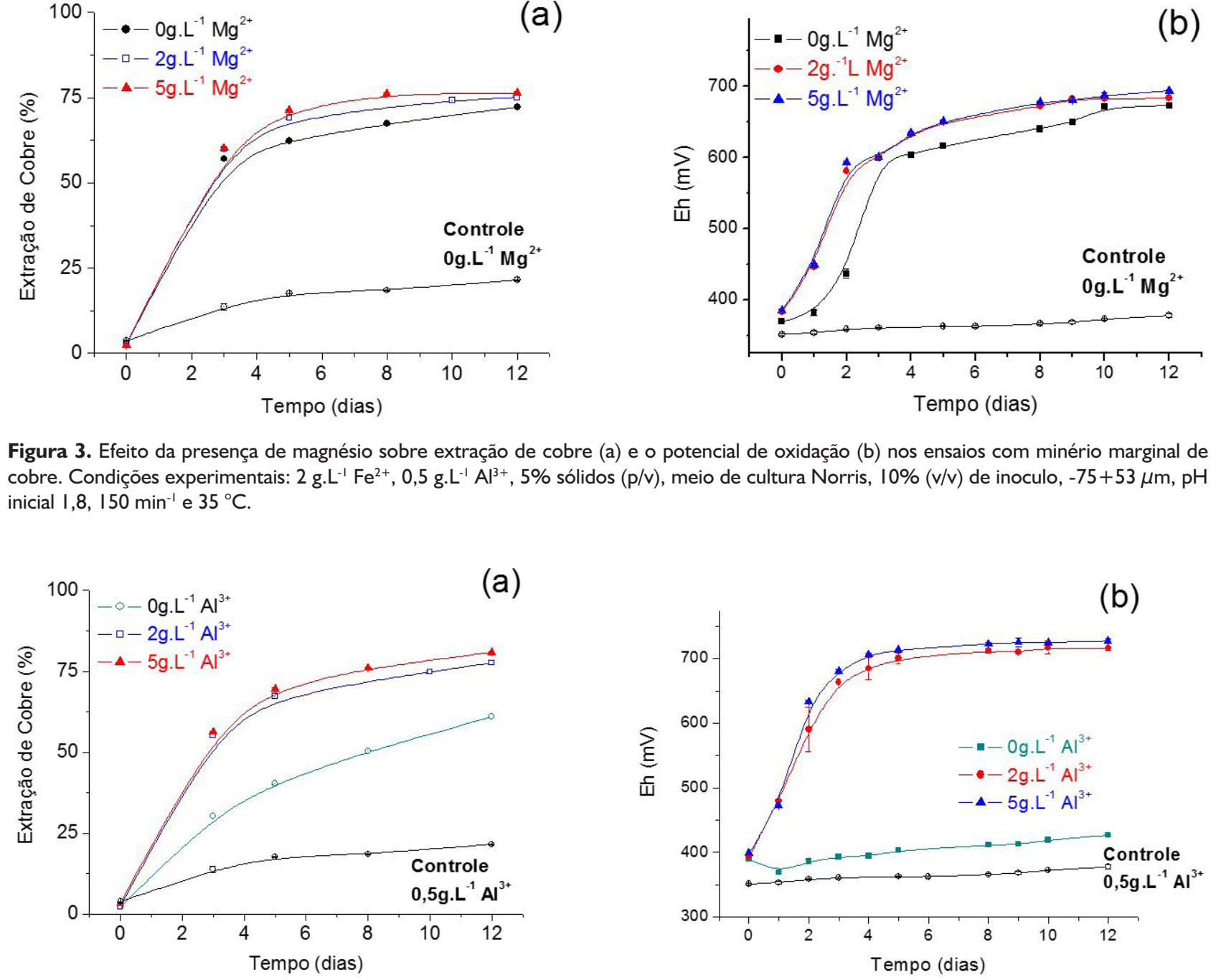

(b)

Figura 4. Efeito da presença de alumínio sobre extração de cobre (a) e o potencial de oxidação (b) nos ensaios com minério marginal de cobre. Condições experimentais: $2 \mathrm{~g} . \mathrm{L}^{-1} \mathrm{Fe}^{2+}, 5 \%$ sólidos (p/v), meio de cultura Norris, $10 \%(\mathrm{v} / \mathrm{v})$ de inoculo, $-75+53 \mu \mathrm{m}, \mathrm{pH}$ inicial I,8, 150 min ${ }^{-1}$ e $35^{\circ} \mathrm{C}$. 
presença de 2 e $5 \mathrm{~g}^{\mathrm{L}} \mathrm{L}^{-1}$ de $\mathrm{Al}^{3+}$ pode ser justificada pelos elevados valores de Eh observados (Figura 4b).

A literatura é controversa quanto ao efeito do alumínio na biolixiviação. Para Ojumu et al. [20], por exemplo, concentrações de até $10 \mathrm{~g} . \mathrm{L}^{-1}$ de alumínio tem um efeito negativo sobre a taxa de oxidação bacteriana do $\mathrm{Fe}^{2+}$ por Leptospirillum ferriphilum. Por outro lado, foi observado que a capacidade de oxidação do $\mathrm{Fe}^{2+}$ por Sulfobacillus thermosulfidooxidans, não foi afetada por concentrações de até $10 \mathrm{~g} . \mathrm{L}^{-1}$ de $\mathrm{Al}^{3+}$ [10]. Além disso, [10] relataram que durante a biolixiviação dessa amostra de sulfetos secundários de cobre houve também a dissolução de minerais portadores de flúor. Segundo os autores, em uma análise por cromatografia de íons, indicou concentrações da ordem de $152,5 \mathrm{mg} \cdot \mathrm{L}^{-1}$ de $\mathrm{F}$, em solução, nos ensaios com o minério marginal. Eles observaram que a adição de sulfato de alumínio ao sistema, de modo a se obter uma razão mássica $\mathrm{Al} / \mathrm{F}=2,0$, reduziu a toxicidade do flúor para - Sulfobacillus thermosulfidooxidans.

No presente estudo, a dissolução de minerais portadores de flúor resultou em concentrações de fluoreto em solução em concentrações próximas a $250 \mathrm{mg} \cdot \mathrm{L}^{-1}$. Como previamente discutido, o flúor é convertido a HF nas condições de $\mathrm{pH}$ dos ensaios de biolixiviação, sendo que este último atravessa a membrana celular e dentro da célula (onde o $\mathrm{pH}$ é neutro) se dissocia liberando íons $\mathrm{H}^{+}$, afetando o crescimento bacteriano. Caso não houvesse minerais portadores de flúor solúveis, os ensaios com $0 \mathrm{~g} . \mathrm{L}^{-1}$ de alumínio deveriam mostrar taxas de biolixiviação de cobre semelhantes às observadas nos ensaios com 2,0 e 5,0 g.L-1 de alumínio. Todavia, tanto a extração quanto o potencial de oxidação foram impactados nessa condição $\left(0 \mathrm{~g} . \mathrm{L}^{-1}\right.$, Figura 4). O alumínio, forma complexos estáveis com o íon fluoreto, reduzindo a concentração de HF [9], a única espécie contendo flúor e capaz de atravessar a membrana celular.

Como a taxa de produção de $\mathrm{Fe}^{3+}$ é menor na presença de flúor e na ausência de alumínio, devido à diminuição da taxa de oxidação de $\mathrm{Fe}^{2+}$ pelos micro-organismos, todo
- $\mathrm{Fe}^{3+}$ produzido é imediatamente reduzido a $\mathrm{Fe}^{2+}$ pela reação de oxidação dos sulfetos de cobre. Isso explica porque o potencial de oxidação do ensaio com $0 \mathrm{~g} \cdot \mathrm{L}^{-1}$ de $\mathrm{Al}^{3+}$ alcançou valores abaixo de $400 \mathrm{mV}$ (Figura $4 \mathrm{~b}$ ), enquanto os experimentos realizados na presença de alumínio alcançaram valores de até $700 \mathrm{mV}$.

\section{CONCLUSÕES}

O estudo da biolixiviação de sulfetos secundários de cobre a partir da utilização de micro-organismos mesófilos é fundamental para o entendimento de processos de biolixiviação em pilhas, dado que esses micro-organismos são predominantes nas condições de temperatura do processo.

A biolixiviação dos sulfetos secundários estudados foi impactada pela liberação de íons fluoreto durante o processo de biolixiviação, o qual atingiu valores próximos a $250 \mathrm{mg} \cdot \mathrm{L}^{-1}$. Quando não houve a adição de alumínio ao sistema, a oxidação do íon $\mathrm{Fe}^{2+}$ tornou-se lenta, não houve elevação do Eh (que permaneceu abaixo de $400 \mathrm{mV}$ ) e a extração máxima de cobre foi de $60 \%$ com o minério marginal. Para contornar o efeito deletério da presença de flúor foi necessário adicionar sais de alumínio ao sistema de forma a se ter relações mássicas Al/F iguais a 2,0. Assim, foi possível atingir valores de potencial de oxidação da ordem de $700 \mathrm{mV}$ e $75 \%$ de extração de cobre, em 12 dias de ensaio em frascos agitados. Tal extração foi obtida em

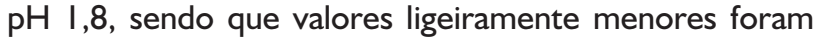
obtidos para valores de $\mathrm{pH}$ abaixo ou acima desse valor, nos ensaios bióticos. A elevada extração de cobre em pH elevado permite inferir um menor consumo de ácido nos sistemas industriais.

\section{Agradecimentos}

Os autores agradecem à CAPES, ao CNPq, à FAPEMIG e à Vale pelo apoio.

\section{REFERÊNCIAS}

I Watling HR. The bioleaching of sulphide minerals with emphasis on copper sulphides: a review. Hydrometallurgy. 2006;84(I-2):8I- I08. http://dx.doi.org/I0.1016/j.hydromet.2006.05.00I.

2 Witne JYE, Phillips CV. Bioleaching of Ok Tedi copper concentrate in oxygen- and carbon dioxide-enriched air. Minerals Engineering. 200 ; I4(I):25-48. http://dx.doi.org/I0.1016/S0892-6875(00)00I58-8.

3 Brierley CL. Biohydrometallurgical prospects. Hydrometallurgy. 20 I0; 104(3-4):324-328. http://dx.doi.org/10.1016/j. hydromet.2010.03.02I.

4 Watling HR, Elliot AD, Maley M, Van Bronswijk WE, Hunter C. Leaching of a low-grade, copper-nickel sulfide ore. I. Key parameters impacting on Cu recovery during column bioleaching. Hydrometallurgy. 2009;97(3-4):204-2I 2. http://dx.doi.org/10.1016/j.hydromet.2009.03.006.

5 Olson GJ, Brierley JAE, Brierley CL. Bioleaching review part B: progress in bioleaching: applications of microbial processes by the minerals industries. Applied Microbiology and Biotechnology. 2003;63(3):249-257. PMid: I4566430. http://dx.doi.org// 0.1007/s00253-003-1404-6. 
6 De GC, Oliver DJE, Pesic BM. Effect of heavy metals on the ferrous iron oxidizing ability of Thiobacillus ferrooxidans. Hydrometallurgy. 1997;44(I-2):53-63. http://dx.doi.org/I0.1016/S0304-386X(96)00030-8.

7 Pina PS. Estudo da biolixiviação e a da lixiviação química de um concentrado sulfetado de zinco. Ouro Preto: Rede temática em Engenharia de Materiais, Universidade Federal de Ouro Preto; 2006. 79 p.

8 Yang C, Qin W, Lai S, Wang J, Zhang Y, Jiao F, et al. Bioleaching of a low grade nickel-copper-cobalt sulfide ore. Hydrometallurgy. 20I I; 106(I-2):32-37. http://dx.doi.org/I0.1016/j.hydromet.20I0.1I.013.

9 Veloso TC, Sicupira LC, Rodrigues ICB, Silva LAM, Leão VA. The effects of fluoride and aluminum ions on ferrousiron oxidation and copper sulfide bioleaching with Sulfobacillus thermosulfidooxidans. Biochemical Engineering Journal. 2012;62:48-55. http://dx.doi.org/10.1016/j.bej.2012.01.003.

10 Sicupira L, Veloso T, Reis F, Leão V. Assessing metal recovery from low-grade copper ores containing fluoride. Hydrometallurgy. 201 I; 109(3-4):202-210. http://dx.doi.org/10.1016/j.hydromet.201 I.07.003.

II Sicupira LC. Biolixiviação de Sulfetos Secundários de Cobre por Sulfobacillus thermosulfidooxidans. Ouro Preto: Rede temática em Engenharia de Materiais, Universidade Federal de Ouro Preto; 2011 . 100 p.

12 Azevedo RDA. Caracterização da diversidade microbiana em biorreatores de biolixiviação de Zinco [trabalho de conclusão]. Ouro Preto: Departamento de Ciências Biológicas, Universidade Federal de Ouro Preto; 2008. 42 p.

13 Carneiro MFC. Lixiviação da calcopirita com soluções de íons ferrico e íons cloreto [dissertação]. Ouro Preto: Programa de Pós-Graduação em Engenharia Mineral, Universidade Federal de Ouro Preto; 2005. I4I p.

14 Muñoz JA, Ballester A, González F, Blázquez ML. A study of the bioleaching of a Spanish uranium ore. Part II: orbital shaker experiments. Hydrometallurgy. 1995;38(I):59-78. http://dx.doi.org/10.1016/0304-386X(94)00037-4.

15 Dopson M, Lövgren LE, Boström D. Silicate mineral dissolution in the presence of acidophilic microorganisms: implications for heap bioleaching. Hydrometallurgy. 2009;96(4):288-293. http://dx.doi.org/10.1016/j. hydromet.2008.I I.004.

16 Deveci H, Akcil A, Alp I. Bioleaching of complex zinc sulphides using mesophilic and thermophilic bacteria: comparative importance of $\mathrm{pH}$ and iron. Hydrometallurgy. 2004;73(3-4):293-303. http://dx.doi.org/10.1016/j. hydromet.2003.12.00I.

17 Santos LRG, Barbosa AF, Souza AD, Leão VA. Oxidação de sulfetos de níquel com microorganismos mesófilos. REM. Revista Escola de Minas. 2008;6I(I):39-46. http://dx.doi.org/I0.1590/S0370-44672008000 I00008.

18 Pina PS, Leão VA, Silva CA, Daman D, Frenay J. The effect of ferrous and ferric iron on sphalerite bioleaching with Acidithiobacillus sp. Minerals Engineering. 2005; I8(5):549-55I. http://dx.doi.org/10.1016/j.mineng.2004.08.01 I.

19 Qiu M, Wang G, Zhang W, Xiong S. Optimizing conditions for bacterial leaching of copper from discarded mines. Journal of University of Science and Technology Beijing, Mineral, Metallurgy. Material. 2006; I3(2): I 08-I I I .

20 Ojumu TV, Petersen J, Hansford GS. The effect of dissolved cations on microbial ferrous-iron oxidation by Leptospirillum ferriphilum in continuous culture. Hydrometallurgy. 2008;94(I):69-76. http://dx.doi.org/10.1016/j. hydromet.2008.05.047.

2I $\mathrm{Li} \mathrm{HM}, \mathrm{Ke} \mathrm{JJ}$. Influence of $\mathrm{Ni}^{2+}$ and $\mathrm{Mg}^{2+}$ on the growth and activity of $\mathrm{Cu}^{2+}$-adapted Thiobacillus ferrooxidans. Hydrometallurgy. 200 I;6I(3):I5I-I56. http://dx.doi.org/10.10I6/S0304-386X(0I)00I67-0.

22 Veloso TC. Biolixiviação de sulfetos secundários de cobre a partir da utilização de micro-organismos termófilos extremos. Ouro Preto: Rede temática em Engenharia de Materiais, Universidade Federal de Ouro Preto; 201 I. $105 \mathrm{p}$.

Recebido em: 29 Set. 2016

Aceito em: 20 Dez. 2016 